\title{
MODEL-BASED PREDICTIVE CONTROL OF AN HVAC SYSTEM
}

\author{
Tamás KARDOS ${ }^{1}$, Dénes Nimród KUTASI ${ }^{2}$ \\ ${ }^{1}$ Technical University of Cluj-Napoca, Faculty of Automation and Computer Science, Department of Automa- \\ tion, Cluj-Napoca, Romania kardos_tamas2007@yahoo.com. \\ ${ }^{2}$ Sapientia Hungarian University of Transylvania, Faculty of Technical and Human Sciences, Department of \\ Electrical Engineering, Târgu Mureș, Romania, kutasi@ms.sapientia.ro
}

\begin{abstract}
This paper presents the application of two model-based predictive control (MPC) algorithms on the cooling system of an office building. The two strategies discussed are a simple MPC, and an adaptive MPC algorithm connected to a model predictor. The cooling method used represents the air-conditioning unit of an HVAC system. The temperature of the building's three rooms is controlled with fan coil units, based on the reference temperature and with different constraints applied. Furthermore, the building model is affected by dynamically changing interior and exterior heat sources, which we introduced into the controller as disturbances.
\end{abstract}

Keywords: control, cooling, MPC, prediction, constraint.

\section{Introduction}

An HVAC system contains heating, ventilation and air conditioning equipment used primarily in office or commercial, industrial buildings, but residential applications are also common. Since in the aforementioned buildings most of the energy is consumed by running heating or cooling equipment, development of an optimal and efficient controller is of the upmost importance.

There are several scientific papers dealing with the control of similar systems:

- the application of a hybrid model-based predictive controller to a residential building is described in [1];

-Fuzzy neural networks and MPC containing genetic algorithms are compared in [2];

- PID and robust PID are presented in [3] and [4]; -Fuzzy controller is combined with PID characteristics in [5].

The system discussed in this research paper represents the air-conditioning unit of an HVAC equipment. The system's controllable inputs are the cooling medium's temperature (Ts) and the fan coil units' signals (FS1, FS2 and FS3). The room temperature is influenced on the one hand by the cooling air supplied by fan coils, on the oth- er hand by the combination of outdoor air temperature, solar irradiance and heat disturbances, such as the presence of people or operation of machines. These factors are modelled using predictions with a degree of uncertainty. Figure 1. shows the system's schematic.

The aim of this paper is to study different model-based predictive controllers in order to control the described cooling system.

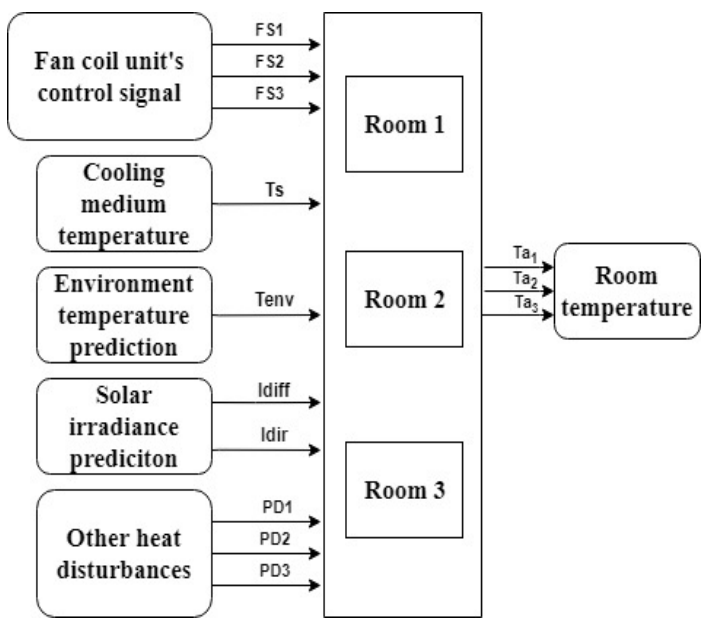

Figure 1. System's schematic 
The paper is organized as follows. In Section 2 , the controlled system's model is presented in state-space form, describing its different inputs and outputs, and the results of an open-loop simulation. The first subsection of Section 3 discusses the theoretical background of model-based predictive control, in the second subsection we present our attempt to apply it on the system, while in the third subsection we design an adaptive model-based predictive controller. Finally, Section 4 contains conclusions drawn, based on our observations.

\section{Controlled system}

The modelled office building consists of three south-facing rooms, each equipped with one fan coil unit. We can describe the building dynamics using a state-space model shown by (1)

$$
\begin{aligned}
& \dot{x}=A x+B u \\
& y=C x+D u
\end{aligned}
$$

where $x$ state vector equals the $T_{a}$ air, and $T_{\text {fal }}$ wall temperatures of the three rooms.

$$
x=\left[\begin{array}{llllll}
T_{\mathrm{a} 1} & T_{\mathrm{a} 2} & T_{\mathrm{a} 3} & T_{\text {fal 1 }} & T_{\text {fal 2 }} & T_{\text {fal 3 }}
\end{array}\right]^{T}
$$

The $u$ input vector is built up from the $T_{e n v}$ environmental air temperature, $I_{\text {dir }}$ direct solar irradiance, $I_{\text {diff }}$ diffuse solar irradiance, $P_{F C U}$ actuator thermal powers, and $P_{D}$ other heat disturbances. $u=\left[\begin{array}{lllllllll}T_{\text {ew }} & I_{\text {dir }} & I_{d i f f} & P_{F C U, 1} & P_{F C U, 2} & P_{F C U, 3} & P_{D, 1} & P_{D, 2} & P_{D, 3}\end{array}\right]^{T}$

The $T_{e n v} I_{d i r}$ and $I_{\text {diff }}$ external weather conditions are equal with the sum of the prediction values and prediction errors modelled with Gaussian distribution. The $P_{D}$ disturbance heat fluxes can also be described using Gaussian distribution using the following equation:

$$
P_{D, i}=\left\{\begin{array}{ccc}
k_{i}+w_{D, i} & \text { if } & 8: 00 \leq h \leq 18: 00 \\
w_{D, i} & \text { otherwise }
\end{array}\right.
$$

where greater heat fluxes $\left(k_{i}\right)$ appearing during working hours change from room to room as written in the (5) equation.

$$
k_{i}=\left\{\begin{array}{lll}
100 & \text { if } & i=1 \\
120 & \text { if } & i=2 \\
150 & \text { if } & i=3
\end{array}\right.
$$

The $y$ output vector consists of the inner room temperatures:

$$
y=\left[\begin{array}{lll}
T_{a, 1} & T_{a, 2} & T_{a, 3}
\end{array}\right]^{T}
$$

The cooling medium circulated through the fan coil units is also a control variable that is limited to values between $T_{s} \in[7,11]$.

Factual prediction data is available for the controller's development. Environmental temperature, direct and diffuse solar irradiance were defined over a 24-hour period, with values changing every hour. The electricity price fluctuation was logged every 15 minutes during the same period.

The system's performance is measured with the cost of operation in euros, which is equal to the sum of the following three costs: consumed electrical energy, deviation from the reference temperature, and the acoustic discomfort.

Further details regarding the controlled system can be found in [6] and [7].

In order to study the system's dynamics we first ran an open-loop simulation. The simulation time was 2 days, the cooling medium's temperature was set to $9^{\circ} \mathrm{C}$. The fan coil units were turned on every day between 8:00 and 20:00, and kept in a turned off state outside this period.

Figure 2. shows the change of temperature in the three rooms marked with distinct colors, with fluctuations between 14 and 27 degrees Celsius, induced by the lack of proper control. Observing Figure 3. we notice the fan coil unit's effect: when turned on the room temperature falls at a remarkable rate, while in the off state it is directly influenced by the external factors. This is presented in Figure 4., where the greatest impact is shown by solar irradiance. One can deduce the direct correlation between the two: greater solar irradiance values introduce upswings in the room temperature. In comparison, changes in environmental temperature have relatively no effect on the inner temperature.

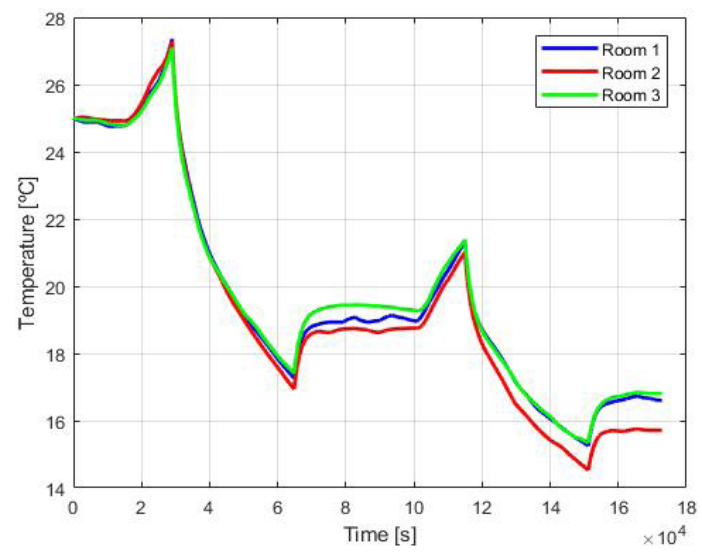

Figure 2. Temperature in the three rooms 


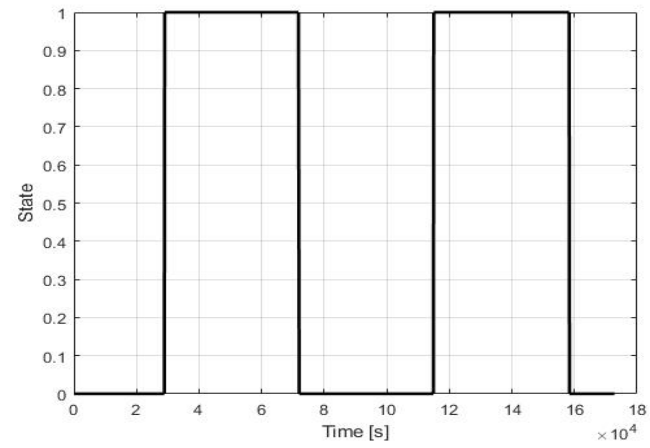

Figure 3. Fan coil units' control signals
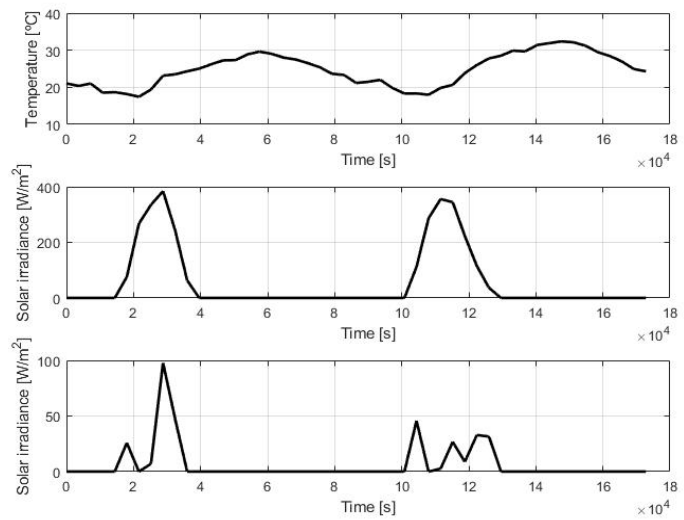

Figure 4. Environment temperature, direct and diffuse solar irradiance

\section{Designed controller}

\subsection{Theoretical background}

Model-based predictive control (MPC) is a widespread process control method of systems that have a known mathematical model, and where the goal is to solve a constrained optimal control problem over a finite horizon. In case of control over a finite receding horizon, we are looking for an optimal control solution that minimizes a cost function:

$$
\begin{aligned}
& J\left(\underline{x}_{k}, \underline{u}\right)=\underline{e}_{k+N}^{T} \cdot F \cdot \underline{e}_{k+N}+\ldots \\
& +\sum_{i=0}^{N-1} \underline{e}_{k+i}^{T} \cdot Q_{k+i} \cdot \underline{e}_{k+i}+\sum_{i=0}^{N_{c}-1} \Delta \underline{u}_{k+i}^{T} \cdot R_{k+i} \cdot \Delta \underline{u}_{k+i}
\end{aligned}
$$

where $e_{k+i}$ represents the control error, $\Delta u_{k+i}=u_{k+i}$ $u_{k+i-1}$ the change of control signal, $N$ the prediction horizon, and $N_{c}$ the control horizon. $Q$ and $F$ represent the positive semi definite weight matrices, while $R$ is the positive weight matrix. After calculating a control sequence by solving the optimization problem for the receding prediction horizon, we only apply the first value. The rest of the sequence is dispersed, because in the next time step they are recomputed [8].

\subsection{Application of classic MPC}

In the first step, we tried to control the system with a state-space, model-based, finite, optimal controller over a receding horizon (MPC). For this, we inserted the MPC Controller Simulink block into our model and created an mpc object that defines the controller's functionality and specifies its characteristics. The built-in MPC Designer tool was one method of doing all of the above, by setting the block's inputs and outputs:

- Manipulated variables: fan coil units' control signals;

- Measured disturbances: actual environmental temperature, direct and diffuse solar irradiance, other heat disturbances and the cooling medium's temperature;

- Unmeasured disturbances: 0;

- Measured outputs: actual room temperatures;

-Unmeasured outputs: 0.

In the following, we set the step time to $1 \mathrm{sec}$, and the cooling medium's temperature to a constant 8 degrees Celsius, in order to have a simpler controller. One of the controller's requirements was to have a linear source model, which our system didn't adhere to, thus a linearization was necessary. A possible way of doing this was by searching for a stabile operating point, that we could linearize the model around, so we could observe the response and stability of the system. To accomplish this we used the operpoint built-in function.

By reason of the controlled system's structure, the control signals sent to the fan coil units can only be of Boolean type, in other words its value is either $0 /$ false or 1 /true. Additionally, this control signal stands at the basis of two calculations: the thermal power transferred into the rooms, and the pump's electric power. When trying to linearize the model, we received - starting with the third simulation step and onwards - a much greater control signal than expected and thus not handled by the controller. This resulted in an error which could only be solved by removing the mentioned calculations and replacing them with constant values. After the linearization was completed, we restored the original calculations, to have the proper working condition.

With the linearization finished, our next step would have been the fine-tuning of the control- 
ler's performance. However, this was not possible because the controller did not have the desired functionality: the control signal was built up only of null-matrices. While investigating the possible causes, we concluded that the controlled system was too complex to be controllable by a classic MPC algorithm.

\subsection{Adaptive MPC with model predictor}

In the following, we examine the applicability of an adaptive MPC connected with an online linear model estimator. Based on the system's inputs and outputs we used a Kalman filter to estimate an ARX regression model (8), which in the end resulted in a linear model.

$$
\begin{aligned}
& y(t)+A_{1} \cdot y(t-1)+A_{2} \cdot y(t-2)+\ldots+A_{n a} \cdot y(t-n a)= \\
& B_{0} \cdot u(t)+B_{1} \cdot u(t-1)+\ldots+B_{n b} \cdot u(t-n b)+e(t)
\end{aligned}
$$

where $A(t)$ is the system matrix, $B(t)$ is the input matrix, $y(t)$ is the output, $u(t)$ is the input and $e(t)$ is white noise.

Afterwards we converted the estimated model into state-space form using ARX-SS transformation. Then the adaptive MPC algorithm would need to use this estimated model, the reference signal and the system model's outputs to predict the new system states, and determine the control signals. Figure 5. shows the presented control loop.

\section{Conclusions}

In this paper we presented predictive control methods applicable for temperature control in an office building. The classic MPC method studied was not suitable for this system because of the model's hybrid characteristics, resulting from the outputs' discrete dynamics. In future, the development of an adaptive MPC is proposed together with a linear model estimator. Further plans include the application of this controller on the studied system.

\section{Acknowledgements}

The presented research project and all the activities involved were supported by Collegium Talentum 2018 Programme of Hungary.

\section{References}

[1] Massimo F., Josh W., Zhenjun M., Julio H. B., Paul C.: Hybrid model predictive control of a residential HVAC system with on-site thermal energy generation and storage. Applied Energy, 187. (2017) 465-479.

https://doi.org/10.1016/j.apenergy.2016.11.041

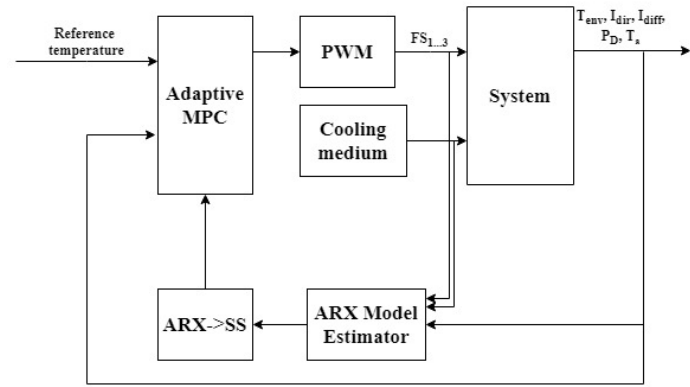

Figure 5. Block diagram of the controlled system

[2] Zhang F.: Building Temperature Control with Intelligent Methods. Electronic Theses and Dissertations, 733 (2014).

https://digitalcommons.du.edu/etd/733

[3] Tashtoush B., Molhim M., Al-Rousan M.: Dynamic model of an HVAC system for control analysis. Energy, 30/10. (2005) 1729-1745. https://doi.org/10.1016/j.energy.2004.10.004

[4] Kasahara M., Matsuba T., Kuzuu Y., Yamazki T., Hashimoto Y., Kamimura K., Kurosu S.: Design and Tuning of Robust PID Controller for HVAC Systems. ASHRAE Transactions, 105/2. (1999) 154-166.

https://www.researchgate.net/publication/236447627_Design_and_tuning_of_robust_ PID_controller_for_HVAC_systems

[5] Huan S., Nelson R.M.: A PID-Law-Combining Fuzzy Controller for HVAC Applications. ASHRAE Transactions, 97/2. (1991) 768-774.

[6] Kardos T., Kutasi D. N.: HVAC rendszer modellezése és modell alapú irányítása. In: A XIX. Műszaki Tudományos Ülésszak, Kolozsvár, Románia, Műszaki Tudományos Közlemények 10. (2019).

https://eda.eme.ro/handle/10598/31161

[7] The 26th Mediterranean Conference on Control and Automation, MED 2018 Process automation challenge. 2018.

http://www.med-control.org/med2018/wp-content/uploads/2018/02/MED2018_Process_automation_challenge_task_details.pdf (letöltve: 2018. február 27.).

[8] László D., Katalin Gy., András K.: Modell alapú prediktív irányítási algoritmus, állapotfüggő Riccati-egyenlet, illetve véges horizontú $D L Q R$ algoritmusok összehasonlítása. In: A XV. Műszaki Tudományos Ülésszak előadásai. Kolozsvár, Románia, Müszaki Tudományos Közlemények 2. (2015) 61-74. http://hdl.handle.net/10598/28549 